\title{
QUAND LES MORISQUES SE MARIAINT...
}

\author{
Yvette Cardaillac-Hermosilla*
}

Les morisques revendiquent par la voix de leurs représentants le droit de continuer à suivre leurs us et coutumes en ce qui concerne le mariage, la mort, les offices religieux, le costume et le langage ${ }^{1}$. Dans ces moments privilégiés de la vie, ils se réunissent pour chanter et danser ${ }^{2}$.

Le mariage est une institution universelle que l'on trouve dans presque toutes les cultures. Il en existe une grande variété, en particulier selon le nombre de conjoints (monogamie, polygamie, polyandrie).

Dans la tradition chrétienne, le rite byzantin, en vigueur depuis le Xlème siècle, célèbre deux cérémonies, celle des épousailles et celle du mariage proprement dit. Dans la tradition islamique, le mariage est un contrat dont les clauses sont définies par le Coran dans la tradition du prophète. Il se prépare avec l'accord des deux familles bien avant la célébration de la fête. L'homme doit se marier s'il n'a pas d'empêchement et peut avoir jusqu'à quatre femmes en même temps. Il peut épouser une juive ou une chrétienne mais les enfants seront musulmans. L'union avec des femmes de religions polythéistes est interdite.

Cette union comporte de nombreuses facettes que la littérature et l'histoire ont examinées de façon répétée: la dimension économique n'est certes pas à négliger. Elle se traduit par un contrat qui fait partie de l'acte social. Il semblerait que l'absence de possession de terres facilite la polygamie. La vision sacrée et religieuse de ce lien est aussi très forte. L'intérêt du mariage est aussi vu comme l'accès au bonheur.

Dans notre étude, nous nous intéresserons d'abord aux moments les plus importants: les préliminaires, le jour de la fête, l'après-mariage. Ensuite,

* Faculté pluridisciplinaire de Bayonne, Université de Pau.

1. Guadalaraja Y Xavier, Fray Marcos de, Memorable expulsión y justísimo destierro de los moriscos de España, Pamplona, Nicolás de Assyan, 1613, 164 f, folio $53 \mathrm{v}$.

2. "Les moments privilégiés de la vie religieuse des Maures se confondent avec les évènements familiaux mariage, naissance, décès, qui sont souvent des occasions pour se réunir, chanter et danser" (DOMínguez OrTiz Antonio et VINCENT, Bernard, Historia de los Moriscos, Madrid, p. 313, p. 91). 
nous essaierons de voir quels rôles jouent ces actes successifs dans la vie du morisque. Et enfin, nous nous demanderons le sens que l'on peut leur donner dans une société en évolution, le XVIème siècle.

\section{LES PRELIMINAIRES}

Les lois chrétiennes vont essayer de se substituer à la législation musulmane de façon de plus en plus pressante surtout après la révolte des morisques de Grenade. Dans les pays mutsulmans, c'est dans le Coran que la plupart des états arabes puisent leurs droits au mariage, soit que les règles religieuses aient par elles-mêmes force de loi, soit qu'elles aient inspiré la législation de l'Etat. Le mariage morisque se déroule selon le titre VIII des lois des Arabes. En particulier, un témoin, homme mûr, sain de corps et d'esprit est chargé de donner la fille à marier en présence des parents. Le fiancé donne à sa promise une dot ou des bijoux, l'alçidaque. Le don de la femme au mari, le consentement, la constitution de la dot sont des actes juridiques qui doivent être établis devant de bons musulmans.

La polygamie est autorisée, et les hommes, en plus des épouses légitimes possèdent des esclaves pour leur plaisir. Cardona nous signale que les morisques se marient très jeunes: les filles à l'âge de 11 ans et les garçons à 12 ans. Cette affirmation n'est pas confirmée par une étude historique sur l'âge du mariage des morisques. Il se situe entre 16 et 18 ans pour les femmes et entre 21 et 25 ans pour les hommes ${ }^{3}$. L'Espagne semble se caractériser dans l'ensemble, chrétiens et musulmans confondus, par un engagement plus précoce que dans le reste de l'Europe. D'après les chrétiens, les relations entre fiancés sont admises avant le mariage, le mariage est parfois consommé avant la cérémonie. Parmi les crypto-musulmans, il n'existe pas de personne vouée au célibat comme les religieuses et le clergé dans la religion catholique.

Dans le contrat de mariage le nom revêt une grande importance. Dans un mémoire adressé au roi en 1567, Francisco Núñez Muley, notable morisque, pour s'opposer aux menaces de la pragmatique du 17 novembre 1566 édictée dans le but de priver les morisques de leurs coutumes ${ }^{4}$, défend l'usage du surnom morisque car avec les surnoms castillans, on perd la trace des personnes et des lignages morisques: "on ne saura pas à qui on a affaire, à qui on achète, avec qui l'on se marie, car on ignorera l'origine du lignage".

3. VINCENT, Bernard y CARRASCO, Raphaël, «Amour et mariage chez les morisques», in Amours légitimes et amours illégitimes en Espagne XVlème-XVIIème siècles, Paris, Publications de la Sorbonne, 1985, p. 147.

4. Foulché-Delbosc, R., «Memoria de Francisco Núnez Muley», in Revue Hispanique, 1901, pp. 205-239. 
Il se traduit souvent dans le nom par le mot Ben ou Aben. En effet, avec l'exil de Grenade après la révolte, puis avec l'expulsion, on passe de la famille lignagère, du fait tribal à la dissociation complète du noyau familial par le jeu des déplacements obligatoires, de l'esclavage, des ventes. Lorsque la situation historique le permet, les groupes agnatiques ${ }^{5}$ se définissent par rapport à un ancêtre commun. Seule compte la filiation paternelle. Le morisque utilise un prénom, un nom et un surnom qui est l'élément le plus important. Les autorités chrétiennes s'attachent à christianiser les premiers au détriment du second.

La dot est l'objet de grandes transactions lors du projet d'union. Naváez donne la liberté et une dot pour leur mariage à Abindarráez et Jarifa qui viennent se présenter à lui comme prisonniers ${ }^{6}$. Les morisques suivent la tradition écrite contenue dans les manuscrits aljamiados qui suivent les coutumes maliquites ${ }^{7}$. Seule la femme apporte une dot. Cependant dans la pratique, l'homme lui attribue certains biens.

Selon la tradition des Wisigoths, la quantité et l'origine des biens sur lesquels la femme peut avoir des prétentions étaient diverses ${ }^{8}$. Les contrats de mariage ou lettres de dot étudiés par Ana Labarta ${ }^{9}$ et Joaquina Abarracín ${ }^{10}$ sont des exemples de ces relations économiques qui précèdent

5. Groupe descendant d'une même souche masculine.

6. RoIG, Adrien, «Sonnet et Comedia: les deux sonnets de El Remedio en la desdicha de Lope de Vega», in Le sonnet à la Renaissance, des origines au XVIlème siècle, Actes des troisièmes jour nées rémoises, 17-19 janvier 1986, sous la direction de Yvonne Bellenger, Paris, Aux Amateurs de Livres, 1988, p. 230.

7. FLORIANO, Luis, Derecho matrimonial en la literatura aljamiado morisca, Oviedo, Universidad, 1972.

8. - Le prix d'achat payé par le mari aux parents de la femme lors des fiançailles se transforme petit à petit en dot. La femme que son mari n'a pas dotée n'est qu'une concubine. Cette dot peut être constituée par des biens mobiliers.

- Le don du matin est ce que reçoit la femme du mari le lendemain du mariage qui montre qu'elle n'a pas de vices cachés (tels que la perte de la virginité chez beaucoup de peuples primitifs). Ce douaire s'ajoute à la dot et peut contenir des biens mobiliers.

- La dot au sens romain ou apport de la femme, est un héritage du code babylonien d'Hammourabi vers 2250 avant Jésus Christ, ce législateur exprima son désir de justice dans les codifications qu'il fit écrire. Il contient surtout des vêtements et des ornements. La femme reçoit aussi de ses parents une part d'héritage des droits. Tout cela est rendu en cas de répudiation.

BRISSAUD, J., Manuel d’histoire du droit privé, Paris, Albert Fontemoing, 1908, 197 p. BENASSAR, Bartolomé, Histoire des espagnols, Paris, Armand Colin, 1985, Tome I, p. 30.

9. LABARTA, Ana «Contratos matrimoniales entre moriscos valencianos», Al-Qanata, IV, 1983, pp. $57-87$.

10. Albarracín Navarro, Joaquina, «Una carta morisca de dote y arras. Granada (1540) y Juan Martínez Ruiz», dans ce même volume.

Une étude à partir de ces contrats de mariage peut apporter de nouvelles informations sur les us et coutumes morisques. La thèse de Maité Lafourcade pour ce type de documents au 
l'acte social. Les manuscrits aljamiados ${ }^{11}$ déclarent que ce que le mari a donné à sa femme lui revient après sa mort. Tandis que tout ce que porte la femme, lui appartient. Si elle l'a acheté sous la domination de son mari cela appartient au mari. Tout ce qui se trouve dans la maison et qu'elle n'a pas apporté, appartient pour moitié au mari et pour moitié à la femme.

Le trousseau fait partie de la dot qu'apporte la mariée. Elle se trouve détaillée dans les inventaires des biens des morisques. $\mathrm{D}^{\prime}$ ailleurs les enfants de milieu modeste sont placés dans l'aristocratie comme domestiques dès l'âge de sept ans. Là ils sont nourris et blanchis et ils peuvent apprendre un métier. Ils restent une dizaine d'années aux termes desquelles ils reçoivent une aide financière ou les éléments de leur trousseau.

Les vêtements et autres pièces de toile nécessaires au ménage sont placés dans un coffre en bois décoré de façon plus ou moins artistique selon les possibilités de chacun. C'est une des pièces essentielles du mobilier dans la maison morisque, qui sert pour le rangement, pour la protection des textiles. Les bijoux sont rangés dans des coffrets aux motifs géométriques qui comportent une signification. Ainsi nous pouvons remarquer sur le coffret morisque du musée de l'Alhambra à Grenade, la répétition d'une étoile à six branches qui rappelle le sceau de Salomon, héros maître des pouvoirs magiques, grâce auquel le grand roi domine les djinns. Des coffrets similaires sont encore réalisés dans les zones berbères de l'Afrique du Nord.

Toutes les grandes religions ont élaboré un système de normes relatives au mariage. En Espagne, la femme est considérée par le pouvoir en place comme manquant de maturité mentale pour passer un contrat; si elle est mariée elle doit toujours compter sur l'autorisation de son mari, si elle est célibataire et adulte, elle doit être assistée par un homme de sa famille. Lorsque son mari est absent le problème juridique est très compliqué ${ }^{12}$. Si elle reste seule, sans capacité juridique, elle peut perdre tous ses biens, mais elle a la possibilité de demander une habilitación por declaración de ausencia ${ }^{13}$. La femme morisque le plus souvent analphabète et ne comprenant pas l'espagnol n'a pas recours à cette possibilité coûteuse et compliquée.

De plus, le pouvoir chrétien s'oppose aux coutumes morisques en ce qui concerne le degré de parenté existant entre les époux.

Pays Basque fournit des pistes intéressantes, Mariages en Labourd sous l'Ancien Régime, Bilbao, Servicio editorial de la Universidad del País Vasco, 1989, 688 p.

Le mot al'arosa, de l'arabe cadeau est passé en castillan et en basque pour désigner le cadeau et la fiancée. PELléN, Txomín, "Gonzalo de Berceo y el euzkera de Zuberoa», (Soule) in Linguae Vasconun, Pamplona, Diputación de Navarra, 1980, p. 42.

11. Kontzi, Reinhold, Aljamiado Texte, Wiesbaden, Steiner, 1974, p. 538.

12. CABrillana CIEZAR, Nicolás, «Almería en el siglo XVI: Moriscos encomendados», Revista de Archivos, Bibliotecas y Museos, Madrid, T. LXXVIII, I, 1975, pp. 41-68.

13. Pouvoir après déclaration d'absence. 
Le 7 décembre 1526, la junte de Grenade se réunit et dit que: "Les nouveaux convertis se marient beaucoup avec des dispenses, souvent pour des cas interdits".

Le 17 juillet 1528, Charles Quint s'adresse aux morisques valenciens:

"Il se pratique beaucoup de mariages parmi les maures entre proches parents à un degré interdit par la loi chrétienne et permis par la loi morisque...Ils peuvent même se marier entre cousins germains fils de frères, à partir de maintenant, il n'y aura pas ce type d'arrangement et on interdira qu'il se réalise"14.

Diego Hurtado de Mendoza nous parle d'une veuve morisque qui se mit à vivre avec un de ses cousins, comme c'est l'habitude entre parents ${ }^{15}$. Ainsi, la différence entre les coutumes des morisques et la législation des vieux chrétiens est génératrice de répression et de conflits. La recherche du mariage endogame est un trait majeur de la famille musulmane ${ }^{16}$. Les chrétiens pratiquent le mariage exogamique facilité par l'interdiction canonique du mariage consanguin.

Par ailleurs, les familles de l'élite morisque qui collaborent avec le pouvoir, prennent volontiers des épouses chrétiennes (Granada, Venegas, Zegríes). Mais dans le peuple, le cas ne semble pas fréquent, même si l'Etat encourage cette pratique par des avantages financiers ${ }^{17}$.

Les coutumes traditionnelles se maintiennent parmi les morisques. La promise doit rendre visite à toute la famille du futur pour qu'on la connaisse. C'est l'occasion de lui passer du henné aux mains en signe de bienvenue, de bonheur et de prospérité. Le rôle accordé à cette plante est important à ce moment de la vie. La pâte obtenue avec les feuilles triturées de cet arbuste mélangées à de l'eau, sert à désinfecter bien sûr mais aussi à la réalisation de dessins plus ou moins artistiques et magiques selon les talents des réalisateurs. Ils peuvent représenter une bordure en triangle le long de la plante des pieds ou des dessins de plantes stylisées sur les mains qui rappellent ceux qui figurent sur les livrets de magie et qui sont destinés à la réalisation de talismans. En fait, ce travail a un but protecteur et il doit favoriser le destin des jeunes époux et annuler tout mauvais sort dans ce moment crucial. Les jours de fête les femmes ont l'habitude de colorer leurs pieds et leurs mains avec du henné et de s'en teindre les cheveux. Elles le font aussi à leurs enfants. Cette coutume existait déjà aux temps des pharaons.

14. Boronat, P., Los moriscos españoles y su expulsión, Valence, 1901, tome I, p. 424.

15. Hurtado de MendozA, Diego, Guerra de Granada hecha por el rey de España don Felipe II contra los moriscos de aquel reino, sus rebeldes, Madrid, Historia dores de sucesos particulares, I, Biblioteca de Autores Españoles, 1946, p. 74.

16. VINCENT, Bernard, «La famille morisque», Historia 16, 57, 1981, pp. 58-66.

17. Voir texte en annexe. 
Les coutumes chrétiennes font un sort à l'esclave ou à l'affranchi. Il ne peut se marier avec un parent de celui qu'il sert car cela constitue un déshonneur pour le maître souillé ${ }^{18}$ par cette alliance. Cependant les esclaves ont le droit de se marier et y sont encouragés par l'Eglise Catholique qui souhaite les voir se soumettre aux sacrements. Lorsque deux esclaves se marient les enfants qui naissent assument la condition servile de la mère. Cependant le maître ne doit pas les séparer. S'ils appartiennent à des maîtres différents, l'Eglise doit obliger l'un des deux à acheter l'autre esclave ${ }^{19}$. Si une femme se marie avec un homme libre sans lui faire part de sa condition servile, cette union est considérée comme nulle et non advenue.

Un rôle particulier est dévolu à la marraine de mariage. Juan Martínez Ruiz dans son étude sur les noms des femmes morisques de $\mathrm{Baza}^{20}$, cite le nom d'une certaine Catalina appelée Almachita qui vient de mãsita qui veut dire coiffeuse, mais aussi selon Pedro de Alcalá, maquilleuse ou marraine de mariage. Cette tradition perdure au Maroc ou on appelle la femme spécialisée dans la préparation de la mariée mesta. Son rôle ne se limite pas à la coiffure, elle dirige tous les rites des épousailles destinés à favoriser le bonheur des jeunes époux dans leur nouvel état. Une vieille femme experte dans tous les usages est généralement chargée de préparer la mariée pour le transfert de sa maison à celle de son époux. Elle doit revêtir selon les traditions les précieux ornements. Les rites religieux se mêlent aux rites magiques en milieu musulman ${ }^{21}$. Une enquête anthropologique nous a permis d'apprendre que ces rites débutent à la puberté. Ainsi, pour conserver la virginité à la jeune fille, on la lie par des paroles magiques sur le métier à tisser et on la délie à la veille du mariage.

Bien sûr, avant de concerter le mariage, les intéressés ou leurs familles ont consulté le devin pour connaitre la bonne issue de leur projet et la date convenable pour réaliser l'acte social. La fête de la Saint Jean semble un moment particulièrement propice pour cette vision du futur. Elle est célébrée dans le royaume de Grenade aussi bien par les chrétiens que par les musulmans. C'est l'occasion de s'adonner à de nombreux rites: les femmes vont filer sous les mûriers pour se concilier l'abondance dans l'année future. Les prédictions concernant le mariage et l'amour sont d'usage car c'est aussi la célébration d'une fête païenne. Nous trouvons différentes mentions dans ce sens dans $L a D_{0}$ orotea $a^{22}$ où $1^{\prime}$ on prévoit à ce moment privilégié une prière

18. Codigos setena partida, lib. V, Tit. VII, loi XVII.

19. Las siete partidas, Tít. V, Ley 2 .

20. MARTínEz Ruiz, Juan, «La onomástica de las moriscas de Baza (Granada), según documentos inéditos (siglo XVI)", in L'expulsió dels Moriscos, Congrés internacional, 380è aniversaire de l'expulsió dels Moriscos, Barcelona, Generalitat de Catalunya, 1994, pp. 309.

21. Albarracín Navarro, Joaquina, Vestido y adorno de la mujer musulmana de Yebala (Marruecos), Madrid, CSIC, Instituto de Estudios Africanos, 1964.

22. Vega Carpio, Lope de, La Dorotea, Espasa-Calpe, Austral, Madrid, 1960, acte III, scène, 4 page 66: 
pour se concilier l'amour. Plus tard, des pronostics sont faits pour connaître la région d'origine du futur mari par la lecture des urines dans un vase de nuit ou dans un récipien plein d'eau, procédé courant dans toute l'Afrique du Nord ${ }^{23}$ si nous en croyons un renégat.

Les invocations pour obtenir l'amour et la haine sont souvent mentionnées dans les archives de l'Inquisition. Nous trouvons aussi d'innombrables recettes dans des livrets aljamiadas de magie:

- pour obtenir la rupture: "tu écriras sur un morceau de roseau les signes magiques et tu le rompras dans la maison où se trouve l'être qui t'aime. Ses sentiments n'y résisteront pas.

- rite magique pour provoquer l'amour: "il s'agit d'inscrire des noms magiques ${ }^{24}$ sur une feuille et de les placer au creux d'un feu lent. L'homme doit venir à l'heure et au jour où l'opération est effectuée ${ }^{\prime 25}$.

Cecilia Pérez ${ }^{26}$, Cándida Gombal ${ }^{27}$ et Ana Francisca de Pedrosa ${ }^{28}$ pré- $^{2}$ tendent exercer des influences magiques pour réaliser des mariages ou les défaire. La dernière est l'esclave d'origine africaine d'un maçon Pedro de Pedrosa. Elle est âgée de 26 ans et entourée par beaucoup d'hommes. Elle dit être apte à la réalisation de mariages difficiles ${ }^{29}$. Cecilia Pérez, esclave moris-

"Gerarda tampoco es ése. Este pienso que es.

Dorotea (lee) "Oración para la noche de San Juan".

Idem, acte II, scène 6, page 204; Madrid, Castalia, 1987, p. 496:

"....cuando estás haciendo tu labor, olvidada de mí, estoy yo estudiando los nominativos de tu casamiento: y la noche de San Juan vi grandes cosas en un orinal de vidrio; y a fe que quién pasó a tales horas, que no venía a burlar. Toribio dijo: Montañés será tu marido".

23. Comillas, Francisco, Un chrétien qui parle comme les morisques, AHN, Mall, livre 860 , folio 261, année 1601.

24. Noms magiques: Uhah Ruhanah Ya Da+nia' il Ya Kakaniyah Ya Sama II Ya Ariyan Ya Mur+yan Karkiyal Ya Urya Saraffiyal Laya Al u ++ Laya Quralih Rit Laya Ri Laya Rus Laya Salsah.

Mahabbatu + fulanin Ibni fulanatin li-fulanatin binti fulanatin hubban sadidan. + "Yuhibbunahum ka-hubbin Llahi wa-lladina amanu asaddu hubban li-Llahi". "Law a+nfaqta ma fi l-ardi gami an. Inna Llahan azizun hakimun".

25. KONTZI, Reinhold, op. cit., p. 726.

26. AHN, INQ, Tol, liasse 2106, $\mathrm{n}^{\circ} 18,1619$.

27. AHN, INQ, livre 990 , folio 48.

28. AHN, INQ, liasse 2106, $\mathrm{n}^{\circ} 17,1617$.

29. Ainsi un noble, Don Pedro Narváez lui promet beaucoup d'argent à condition qu'elle facilite au moyen de sortilèges son mariage avec une grande dame Doña Antonia de Soto qui vivait chez Don Antonio Herrero, chroniqueur du roi. Elle donne des assurances au prétendant en lui disant qu'elle aura l'aide de Hernando de Vera Sauca qui sait lire dans les lignes de la main et qui possède son propre démon familier enfermé dans une fiole. Pour le succès de l'opération il a besoin d'un bout de tissu du vêtement de la victime pour le mettre sur un crapaud. L'esclave s'approche donc de la dame le troisième jour de Pâques et essaie pendant la messe en l'Eglise de Notre-Dame del Buen Suceso de lui en couper un morceau. 
que de Grenade envoyée en Castille, âgée de trente ans, connaissait aussi deux prières qui permettaient d'attirer les hommes en tenant entre les doigts une pierre et en montrant une étoile.

La prière à l'étoile est utilisée par les vieux chrétiens et par les morisques dans de nombreuses variantes. En 1537, nous relevons une formule complexe pour réaliser les désirs amoureux chez une vieille chrétienne:

"Estrelle çafia que por nombre tienes María, conjúrote con Dios y con Santa María, tres ramos de amor tienes, todos me los quieras dar o emprestar para fulano, salga el uno y se lo ponga y dele por el corazón que no olvide mi amor, salga el otro y dele por el sentido que no me eche en olvido, salga el otro y dele por las entrañas que no olvide mis palabras, en cama no duerma, ni pueda reposar que venga a mi querer y a mi mandar dándome lo que tuviere".

Le pouvoir de Dieu et celui de la Vierge viennent s'ajouter aux forces astrales et remplacent celles des prophètes. De la sorte cette incantation se veut plus puissante. De telles formules sont prononcées par les chrétiennes et les morisques en voie d'assimilation en Castille. Comme nous pouvons le constater, tous les moyens sont bons pour obtenir l'amour de l'homme désiré passionnément. Cependant, le rythme ternaire antérieur est ici réitéré avec l'utilisation des trois tiges qui agissent en guise de véritables baguettes magiques par le simple contact, il se reproduit dans l'invocation de l'étoile, de Dieu et de Marie. Le nombre trois dans la tradition iranienne possède un caractère magico-religieux, il unit pensée, parole et action comme ici ${ }^{30}$. Trois actes consécutifs sont exprimés dans cette formule et nous les retrouvons dans les contes merveilleux. L'accomplissement de trois actions permet le succès de l'entreprise, elles forment un ensemble indissociable. La Cabale qui a multiplié les spéculations sur les nombres fait un sort tout particulier à tout ce qui est ternaire: l'agent, le verbe et l'objet.

Le 19 décembre 1539, nous lisons une formule similaire mais avec l'économie de l'invocation de la Vierge et de Dieu dans le procès d'une sorcière morisque, avec la même utilisation des trois baguettes ou branches mais les parties touchées sont différentes et l'une d'elles est oubliée ${ }^{31}$ :

"Señora estrella, tres ramos hay en ti, endónamelos tú a mí, el uno des a fulano en la cabeza, que le viniese mentes de su bienquerencia de una mujer, y el otro que le viniese mientes de su buen amor, y el otro en las espaldas que le viniese mientes della y de sus buenas hadas".

Mais la dame s'en rendit compte, elle poussa un cri et les personnes présentes se saisirent de la coupable qui fut remise à l'Inquisition avec son complice. Ce dernier avoua aussi qu'il aurait fabriqué un onguent pour enduire doña Antonia afin de la soumettre à la volonté de son prétendant.

30. GarCía Gómez, D.E., «Usos y supersticiones comunes a Persia y a España», in Al-Andalus, XXIII, 1957, pp. 459-462.

31. TOlEDo, Lucía de, AHN, INQ, Tol, liasse 198/3. 
Cette incantation réalisée sans coiffe avec les cheveux dénoués, les mains jointes et tendues vers le ciel, les pouces croisés met en oeuvre tout le pouvoir féminin. Par analogie, l'attitude de séduction et l'invocation s'unissent pour influencer le retour d'un mari absent. La recherche d'un rite complet (paroles, gestes, attitudes) permet en magie d'espérer le meilleur résultat. Cette image va s'installer dans le folklore et dans les contes merveilleux pour enfants. Ici nous en avons les éléments essentiels: l'étoile qui un jour rejoindra la baguette magique, la femme fée aux longs cheveux.

Ces diverses incantations à l'étoile reflètent une longue tradition fólklorique du Moyen-Age qui se trouve recueillie dans une chantefable du XIIIème siècle en vieux français. Un chevalier chrétien au nom arabe, Aucassin, prononce une variante poétique pour l'amour d'une ancienne esclave sarasine, Nicolette, la futée. Elle mêle élaboration savante et naïveté populaire dans un enchaînement par reprise qui unit la seconde et la deuxième partie de l'oeuvre ${ }^{32}$. Les invocations se présentent comme de bonnes recettes à utiliser au moment opportun, mais elles dépassent cette dimension utilitaire. Il ne semble pas nécessaire d'insister sur la permanence des structures des invocations et même sur leur contenu avec une grande variation sur les buts choisis. Elles se transmettent par les femmes surtout mais sûrement aussi par les hommes chez les morisques lorsqu'il s'agit d'aller chercher des connaissances dans un livre. Ce sont surtout eux qui connaissent encore l'alphabet arabe.

L'Estrella doncella est la tête des neuf étoiles que l'on évoque tour à tour. Ce n'est qu'un rappel de l'imprégnation astrologique. L'étoile dite vierge est parfois nommée Estrella Diana et donc liée à la déesse ${ }^{33}$.

Les formules pour favoriser l'amour ou conjuros amatorios, servent pour tout un ensemble de rites utilisés à des fins de magie érotique par un grand nombre de femmes pour leur propre compte ou pour celui de leurs clients. Elles montrent à travers les déclarations des accusés et indépendemment de l'idéologie inquisitoriale, l'affleurement de croyances et de mythes, d'une culture qu'il faut décrypter et reconstruire, car pendant longtemps elle a été niée par le discours dominant. Elle semble liée à un héritage archaïque de représentations toujours partagées par de nombreux membres des classes rurales. Dans ces scénarios rituels, il est nécessaire de reconstituer les règles du jeu qui ne présentent qu'une apparente incohérence.

Souvent, il s'agit de soumettre à son insu et contre son gré un amant potentiel indifférent ou de paralyser les ardeurs d'un autre. La magie naturelle (aphrodisiaque) se mêle à l'invocation de forces surnaturelles (génies, saints,

32. Aucassin et Nicolette, Paris, Flammarion, 1984, p. 123.

33. DELPECH, François, «Systèmes érotiques et mythologie folklorique dans les "Conjuros Amatorios", XVIème-XVIIème siècles", in Amours légitimes, anours illégitimes en Espagne (XVIème-XVIIème siècles), Paris Publications de la Sorbonne, 1985, pp. 213-229. 
ou démons). Une scène se joue avec quatre personnages: le client, l'invocatrice, l'entité conjurée et la victime. La femme se passe parfois d'intermédiaire et réalise alors elle-même les rites. Ces pratiques reposent sur toute une mythologie érotique (valeur de l'étoile, des rois mages, de divers saints). Les textes sont rimés et contiennent des allitérations, des images des métaphores récurrentes qui constituent un langage propre, celui de l'incantation obsédante et hallucinatoire. Les morisques, dans les régions où ils sont minoritaires surtout, récitent les pseudo-prières adressées à des saints, Marthe, Christophe ou Hélène.

L'invocation vise à envoyer au moyen d'un transfert d'une personne à l'autre, un tourment, une ardeur communicative. L'organisation imaginaire repose sur une sexualisation de l'espace et du mouvement. Elle rappelle un certain nombre de rites initiatiques et de contes merveilleux. L'importance de la vie érotique apparaît dans cette société où elle joue un rôle structurant tant du point de vue psychique que social. Le fameux diable boiteux présenté comme le plus fort de tous, est apparenté par son infirmité au forgeron magicien des traditions indo-européennes. Il fait partie des magiciens liés et lieurs précipités du ciel dans les zones inférieures. Son rôle dans la magie est sans doute très ancien ${ }^{34}$.

Dans la société morisque, comme dans toute société structurée, le mariage est une grande affaire et les préliminaires constituent la partie la plus importante du point de vue anthropologique ou socio-économique. La domination par le pouvoir chrétien n'a pas beaucoup changée les coutumes, surtout pour les morisques continuant à vivre dans les aljamas. La rupture se fait avec l'exil, l'esclavage, la pauvreté et l'immersion en milieu chrétien où les coutumes de la société dominante sont introduites à des degrés différents avec une insistance particulière avec la réforme du mariage catholique.

\section{PENDANT LE MARIAGE}

Le rite occupe une place importante: il traduit le caractère sacré et en tout cas solennel de l'engagement; il exprime le désir d'une reconnaissance sociale de l'union; il rend possible un contrôle. Nécessaire à la validité, voire à l'existence même du mariage, la forme se présente aussi comme un instrument de preuve du lien conjugal. Le Concile de Trente, en 1563, sous la pression du pouvoir monarchique, décrète que le mariage doit être célébré devant le curé de la paroisse de l'un des deux fiancés et devant deux témoins afin d'assurer une publicité du mariage qui permet à l'Eglise d'en contrôler la régularité. De ce jour, les mariages clandestins sont poursuivis et l'opposition devient patente entre mariage et concubinage.

34. Petit boucs boiteux de la Grèce antique, caractères magico-rituels des jeux à cloche pied, jambe de bois, béquilles, baton cheval utilisé pour les voyages dans les airs. 
Nous possédons des gravures italiennes du XVIème siècle (estampes $\mathrm{Ob} 51$ a) qui nous permettent d'avoir une idée précise de la façon dont s'habillent les morisques dans la rue au quotidien. La tenue courante permet de distinguer ${ }^{35}$ la classe sociale de l'individu. Elles sont réalisées par Diana Ghisis ${ }^{36}$ dite Scultori Mantoano qui naît à Mantoue vers 1536. Les vêtements de mariages sont toujours spéciaux, pourvus de diverses broderies de couleur dorée, ils se prêtent à cause de leur valeur. Les dames morisques portent des tuniques courtes, des bas de chausse tirebouchonnés. Le morisque Francisco Nuñez Muley s'adresse au roi pour protester contre l'ordonnance du 17 novembre 1566. Il déclare que ces vêtements de caractère régional distinguent son peuple. On garde les habits de noce et de fêtes. On se les transmet pendant trois ou quatre générations. Les chaussures fabriquées à base de cuir et de liège influencent celles des chrétiens.

Dans le rituel du mariage, certains éléments revêtent une signification. Ainsi en est-il de la ceinture, du lien de la taille ou de la tête, et de la toque, les éléments importants du point de vue magique. La ceinture appelée $m a-$ damma au Maroc, ou hizam par les populations d'origine berbère comporte beaucoup de variétés ${ }^{37}$. Elle se porte sur le caftan, elle est en cuir pour les hommes et en soie, laine ou velours sur une armature quelconque pour les femmes qui la portent le plus souvent brodée en soie et or. Elle est utile pour retenir les vêtements, pour porter des objets divers et parfois même les enfants $^{38}$. Elle sert aussi d'ornement à la ceinture ou à la tête. Elle évolue suivant le milieu dans sa matière, laine, coton, soie, et peut arriver à déterminer la classe sociale de l'utilisateur. Les modèles sont différents suivant la fabrication artisanale de la ville ou de la campagne, suivant la richesse de l'individu, selon son sexe. Celle qui se porte au Maroc est originaire d'Espagne par son tissage et la technique de la teinture ${ }^{39}$. Pedro de Alcalá témoigne de

35. Navaregio, p. 59, description de 1526, in BOSCH VILÁ, Jacinto y HOENERBACH, W., Andalucia islámica textos y estudios, Granada, Universidad, 1986 (Biblioteca universitaria de Granada).

Les femmes du peuple portent de zaragïelles (pantalons) et une alcandora (tunique) en toile $\mathrm{d}^{\prime}$ Anjou teinte. Ce qui semble le plus curieux dans le costume des grenadines ce sont les bas de chausse ou calzas: de simples housseaux de cotonnade blanche longs d'environ un mètre, attachés au dessus du genoux par une bande de jarretière, qui descendent sur la jambe en faisant de multiples plis ce qui se porte encore au Maroc et qui revient à la mode en Europe. De la sorte les jambes paraissent très grosses. A la maison les femmes s'habillent différemment avec une chemise courte et des chausses bouffantes et par dessus tout une longue chemise de lin, les pieds nus.

36. Joun, Jeanne, «Document sur les costumes des musulmans en Espagne», in Revue africaine, 1934, LXXV, n³58, pp. 43-46.

37. GONZÁlBEZ BuStOS, Guillermo, «Huellas andalusíes en el vestir marroquí», in Contribución al estudio de la historia de Marruecos, CBET 16, 1977, pp. 67-109, esp. p. 79.

38. AlbarRacín, Joaquina, «Joyas Moriscas Andalusíes en la tradición femenina tetuaní», in Le cinquième centenaire de la chute de Grenade 1492-1992, pp. 57-68, CEROMDI, Zaghouan, 1992.

39. GONZÁlbEZ Bustos, Guillermo, op. cit. 
son usage parmi les morisques. Elle existait aussi chez les mozarabes sous le nom de Qriza avec un double sens, celui de longue ceinture dont on enroule la taille, ou celui de turban dont on enroule la tête. Dans la relation de Dopper, elle fait partie du costume des morisques en Afrique du Nord en 1659. Elle s'appelle Kurzig, mot d'origine berbère avec la racine krz qui signifie nouer. L'action de nouer est essentielle dans la pratique magique car grâce à ce geste on peut nouer toute chose. En particulier, pour le mariage, les mariés noués par leur ceinture ou leur lien à la tête ne pourront être noués par leurs ennemis qui pourraient empêcher la consommation du mariage $e^{40}$.

Le voile ou almalafa, est une pièce de coton, de lin ou de soie avec laquelle les femmes morisques s'enveloppent et se cachent la face. L'épouse porte la alcandora ainsi que les femmes qui servent le repas de noce. Les soies de Grenade sont réputées. Leur fabrication, leur vente sont à l'origine de grosses fortunes. Les éleveurs de vers à soie louent les terres où ils cultivent les mûriers nécessaires. Au XVIlème siècle ce tissu est tellement abondant que tout le monde en porte aussi bien les gens du peuple que les nobles. Mais pour les femmes il est de couleur vive et pour les hommes de couleur noire. Ces derniers s'habillent avec des tuniques, des chausses ou des sarouels. Ils se protègent grâce au burnous ou albornoz. Les vêtements morisques sont très mal acceptés par les autorités chrétiennes qui les considèrent comme un signe d'identité musulmane. Cependant des aristocrates les adoptent, Isabelle la Catholique n'en est pas le moindre exemple ${ }^{41}$.

40. GUERRY, Vincent, La vie quotidienne dans un village baoulé, Abidjan, INADES, 1970, p. 86. Chez les Baoulés, on attache aux mollets et aux poignets des fils lors du rite de la rupture du veuvage. Le veuf avant de se remarier doit aussi procéder à la rupture de la ceinture qui lui serre les reins depuis le premier goûter. Il le fera juste après une relation amoureuse avec une femme qu'il n'épousera pas, juste avant de choisir l'épouse de son choix. La femme aussi doit couper sa ceinture après s'être unie une nuit à un étranger de passage.

41. CARDAILLAC, Louis, Les convers et le pouvoir en Espagne, XVème-XVlème siècles, Aix-Marseille, Université de Provence, 1990. Les morisques se différencient des chrétiens par leurs vêtements. Mais entre eux ils marquent aussi leur appartenance sociale. Ceux qui sont aisés portent des vêtements de soie avec des ornements de la même matière ou de drap (Mármol Carvajal, Historia de la rebelión y castigo de los moriscos del reino de Granada, Málaga, Editorial Arguval, [1600] 1991, p. 161). Les plus humbles aiment porter des couleurs vives et les femmes se parent de nombreux bijoux. La marlota (manteau très décoré, brodé d'or et d'argent). Ce vêtement est le seul que puissent porter les femmes. Elle est en soie aux couleurs vives et peut s'appeler azedria: "Una marlota marilia / todas de Mahomas de oros / E mil arábigas cifras" in VeGA CARPio, Lope, "San Diego de Alcala», in Teatro, Madrid, Aguilar, 1961, la almalafa et l'alquicel (II est de couleur blanche et à l'air d'une cape) constituent la base du vêtement morisque. Ce sont des manteaux amples qui furent interdits. Ils portent aussi l'albornoz, vêtement simple avec un grand capuchon. Une toque ou turban fait partie du vêtement masculin car le morisque a l'habitude de s'enrouler d'une grande bande de toile à la tête. Beaucoup d'entre eux portent les gregüescos et une espèce de chemise large el sayo. Ils chaussent des alpargatas (paysans) ou borseguies (morisque aisé) ("El morisco que ponía / duras alpargatas de esparto / ahora trae borceguíes / argentados, alosado / vestido de terciopelo, / en tafetán aforrado"). 
A l'occasion du mariage, on procède au rite de la purification. La pratique des bains est courante chez les morisques. Les chrétiens considèrent cette habitude comme impudique. On peut voir de très beaux bains maures à l'Alhambra de Grenade. Cet acte de purification physique et religieuse se célèbre avec beaucoup de pompe dans la région de Grenade où les fiancés se rendent aux établissements publics avec beaucoup d'amis. Ils y reçoivent des soins corporels sophistiqués grâce à quelques spécialistes de la préparation des mariés.

Les tatouages ${ }^{42}$ sur le corps, les bras, les jambes, le visage des jeunes filles ou des hommes sont aussi réalisés dans un but esthétique et magique. Les procès d'Inquisition nous les signalent lorsque les morisques ou les africains en avaient sur leur visage ${ }^{43}$. Avant le mariage la fiancée qui s'était engagée devait porter un voile de couleur, à l'origine en soie. Elle devait aussi, avec l'aide des membres de sa famille ou avec ses amies, tisser le lin que lui donnait le futur époux. Les femmes pour paraître plus belles se maquillent. Elles utilisent divers produits pour leur chevelure qu'elles laissent libre ou qu'elles retiennent avec une couronne ou un diadème $^{44}$.

L'utilisation de parfums suit la longue tradition orientale. Ce mot vient du latin per fumen (par la fumée). L'origine linguistique indique que depuis des siècles on brûle des substances aromatiques pour en humer des odeurs balsamiques aussi bien que pour rendre hommage aux divinités. Leur usage est très répandu autant chez l'homme que chez la femme. Certains sont particulièrement appréciés: le jaluq parfum safrané, le sa'fran safran, l'abir ambre grise, l'anbar ambre naturelle, le sukk espèce de parfum noir, le galiya et le misk musc. Le safran provient du coeur d'une variété de crocus. Il est réputé pour ses qualités gustatives et apéritives et il sert aussi à la fabrication de divers parfums ou au maquillage en particulier pour estomper la forme des yeux et leur communiquer un dessin allongé ${ }^{45}$. Les anciens mettent pendant les festins des couronnes sur la tête. Ils attribuent au parfum du safran la puissance de procurer le sommeil réparateur et des songes agréables. Le musc est apporté d'orient, c'est une huile essentielle qui suffit à donner à un tissu, une odeur qui persiste pendant des années dès lors même qu'il est exposé à l'air. Un philtre, une boisson, des drogues peuvent être administrés tout à fait à l'insu de ceux qui les absorbent. Pour le parfum, il en est différemment, on s'enivre avec plaisir: Dans les cérémonies magiques et religieuses, ils sont

42. Bouchard, Ahmed, Les crypto-musulmans d'origine marocaine et la sociêté portugaise du XVlème siècle, Montpellier, thèse, 1987, 3 volumes, Tome I, p. 117: tatouage d'une jeune fille.

43. Cardaillac-Hermosilla, Yvette, «Esclavage et magie chez les nouveaux chrétiens en Espagne», Revue d'histoire maghrébine, Tunis, 1984, n 36-37, p. 128, Juan Maroto, année 1563, AHN, INQ, Procès, liasse 193/14 (esclave).

44. Caro Baroja, Julio, Los moriscos del Reino de Granada, Ensayo de historia social, Madrid, Ediciones ISTMO, 1957, 285 p.

45. RuvaSSON, Marguerite de, Les parfums magiques, Paris, Edition H. Durville, 1980, p. 70. 
prodigués autour des autels où s'accomplissent des mystères. Par leurs vertus, ils facilitent les extases, les visions, les hallucinations. Dans le mariage les parfums agissent comme agents d'excitation de l'amour physique. Ils contribuent au culte de Vénus. Les senteurs pénétrantes contribuent à la séduction et effectuent une action troublante sur les centres nerveux et émotifs.

A toutes les époques, les formules des parfums ont la réputation d'exciter l'action du système planétaire, comprenant pour le soleil: le safran, l'ambre et le musc essentiellement avec $d^{\prime}$ autres ingrédients comme le bois de baume, le bois de sainte Lucie, les fruits de laurier, le girofle, la mire et l'encens. Mêlés avec art, ils forment un parfum magique s'alliant avec toutes les splendeurs de l'astre du jour. Le Khôl sert à maquiller les yeux. Il est d'origine égyptienne, apprécié à Rome. On l'utilise pour faire les cils et pour prolonger la longueur et la forme en amande. Jeanne, d'origne barbaresque, esclave d'Alvaro Dura d'Antequera, fut accusée d'avoir assisté à des mariages de maures alcoholada y anozegada la boca selon leur usage. Ils s'appelaient les uns les autres par des noms musulmans, ils dansaient à leur façon, ils mangeaient du couscous et ils remerciaient Mahomet ${ }^{46}$.

On trouve dans les bijoux des morisques de l'ambre, des perles et des turquoises montées en bagues, boucles d'oreilles, colliers, bracelets et pendentifs ${ }^{47}$. Aznar Cardona ${ }^{48}$ affirme que les femmes morisques portent des plaques d'argent sur la poitrine, d'autres suspendues à leur cou, des colliers, des boucles d'oreilles, des bijoux en forme de main, du corail, sur leurs vêtements de couleur. Les femmes en agrémentent leurs toilettes. Certains sont constitués de plaques d'or ou d'argent avec des inscriptions en lettres arabes, versets du Coran ou noms de Dieu. Leur port par les morisques est interdit par de nombreuses ordonnances.

Joaquina Albarracín fait une étude des bijoux que porte la mariée morisque, de El Andalous à la région de Tétouan et ses observations montrent des correspondances entre musulmans d'Espagne, morisques et marocains. La tradition s'est maintenue au cours des siècles. Ces objets de valeur ne peuvent être possédés par tous, on les prête à celui qui ne peut les acquérir. A la campagne, ils sont en argent, alors qu'à la ville ils sont en or. On les retrouve dans les mêmes circonstances dans toute $l^{\prime}$ Afrique du Nord et dans les costumes régionaux espagnols (charros de Salamanque).

46. García Fuentes, La Inguisición en Granada en el siglo XVI, Granada, Diputación provincial, 1981, cas. 36, p. 166.

47. MartíneZ RuIZ, Juan, Inventarios de bienes moriscos del Reino de Granada, siglo XVI, Linguística y Civilización, Biblioteca de dialectología y tradiciones populares, CSIC, Madrid, 1972, p. 18.

48. "Iban de cuando en cuando muchas mujeres hechas unas debonaderas, con diversas patenillas de plata en los pechos, colgadas de los cuellos, con gargantillas, collares, arracadas, manillas, corales y con mil gaiterías y colores en sus trajes y ropas" (AZNAR CARDONA, Pedro, Expulsión justificada de los moriscos españoles, Huesca, Pedro Cabarte, 1612, pp. 5-6, 202 p. $+158 \mathrm{p}+6 \mathrm{ht})$. 
Un de ces colliers, appelé collier d'orge, se caractérise par ses pendentifs allongés, représentant les grains, symboles d'abondance et de fertilité, et il porte au centre une main de Fatma en guise d'amulette protectrice du mauvais oeil. Les bracelets qui entourent les chevilles ${ }^{49}$ que l'on voit aussi en Orient, représentent le lien qui, selon les croyances populaires, doit préserver de tout mal (la personne étant liée, on ne peut refaire l'opération pour lui jeter un nouveau sort). De nombreux bijoux sont ornés de corail qui est connu pour sa vertu de protéger des maux jetés par le regard jaloux. Les productions artistiques des orfèvres morisques sont multiples. Elles ont un triple emploi: elles montrent la richesse de la famille de celle qui les porte, c'est un recours en cas de besoin, elles ont le plus souvent un sens protecteur. En outre, elles possèdent une qualité artistique qui va disparaître avec les interdictions. Enfin, elles s'associent souvent avec la coiffure ou le vêtement comme le montre le bandeau de front garni de pierres de couleurs rouges et vertes qui pouvait parfois être remplacé par une petite toque ronde, elle aussi abondamment travaillée $e^{50}$.

Ignacio de las Casas ${ }^{51}$ énonce les interdictions concernant ces précieux objets dans sa déposition au synode de Guadix: "Nous ordonnons que personne n'inscrive de prières morisques sur des talismans pour des malades ou pour d'autres personnes".

En outre les bijoux, portant des lunes, des soleils ou des inscriptions en arabe sont interdits. On ordonne la destruction de ceux qui existent déjà dans un délai de deux mois et les orfèvres ne doivent plus en fabriquer. Les textes de l'Inquisition nous font part des problèmes divers que leur confection ou leur port entraînait. Les autorités ecclésiastiques rédigeaient des ordonnances pour en empêcher l'utilisation ${ }^{52}$. Certains bijoux grenadins, qui ont été trouvés au mont El Reyezuelo près de Berchules (Grenade) ${ }^{53}$, peuvent nous donner une idée précise des réalisations morisques.

Lorsque les nouveaux mariés arrivent dans la maison du marié, ils doivent franchir la porte du pied droit pour favoriser le sort. Des traditions bien établies sont suivies par toute la famille. Ainsi les parents de la jeune fille l'offrent à ce moment-là à son futur époux.

Le cortège nuptial se fait à dos de mulet. En tête pour guider est placé un animal de couleur noire, la mariée le suit sur un autre de couleur blanche.

49. "Ajorca" morisque.

50. AlbARRACÍN, Joaquina, "Joyas moriscas andalusíes en la tradición», in Le Vème centenaire de la chute de Grenade 1492-1992, Tunis, CEROMDI, 1993, pp. 57-68.

51. Ignacio de las Casas, pragmatiques du synode de Guadix.

52. Statuts de l'évêché de Badajoz, 7 mai 1583, ADB, antigua diócesis, vol. ms, sala I, est. $8, n^{\circ} 2$, LIB V, TIT XIV, añadido al capítulo 9, folios 276-285: "Advertiréis a los dichos convertidos no traigan, ellas ni ellos, patenas ni otras cosas esculpidas, manos y lunas o letras moriscas, ni las pongan a sus criaturas, ni pinten en sus caras con apercibimiento".

53. MARTíNEZ RuIZ, Juan, Inventarios de bienes moriscos... 
Lorsqu'ils sont obligés de se marier à l'Eglise, ils s'y dirigent ainsi. La fiancée reste couverte par son voile et elle ferme les yeux et la bouche quand elle découvre son visage, par respect et modestie sans doute, mais aussi pour qu'aucun démon malveillant ne l'envahisse et pour ne pas croiser un regard jaloux qui pourrait lui lancer le mauvais oeil au seuil de sa nouvelle vie.

La cérémonie, lorsqu'elle suit le rite musulman, a lieu à la maison: on lit le Coran puis on fait des aumônes ${ }^{54}$. Elle comporte des chants en l'honneur de Mahommed. Lorsque le rite chrétien est imposée, les femmes morisques continuent de pousser des cris de joie appelés alhuelulas. Souvent, en sortant de l'Eglise, le rite musulman est célébré dans l'intimité du foyer. Alors les morisques se livrent à leurs danses et chants traditionnels. Aux XVIème et XVIIème siècles de nombreux ouvrages religieux condamnent ces manifestations considérées comme d'origine diabolique. Dans cette expression du corps, l'homme se laisse aller à son exhibition. L'Eglise qui veut favoriser l'élévation de l'âme réprouve d'ordinaire cette agitation et plus encore quand elle semble révéler la culture musulmane et l'adhésion à une autre religion. Les rondes populaires étaient cependant fréquentes dans les festivités. Les danses peuvent faire gagner des prix si elles sont réussies. On loue Mahommed au son du tambourin adufe, de la vielle, des timbales, des trompettes. On entonne des chants d'amour anexires. Leilas sont les chansons nocturnes accompagnées par des orchestres ou zambras, composés de tambours et d'instruments à vent et à cordes. Les magitas ont du tambourin pendant la fête. L'uléma part lorsqu'on commence à jouer et à chanter. Pendant une période de 74 ans environ, la musique morisque est soumise par les autorités chrétiennes à un processus d'acculturation (1492-1566) qui va la conduire à se réfugier en Afrique du Nord et en d'autres points du monde islamique où elle va se transmettre par la transmission orale.

Dans le Royaume de Grenade, il existe un impôt appelé Tarcón qui est payé pour les zambras et fêtes des morisques à un responsable appelé alcaide de juglaras y juglares au bénéfice de l'état. Il est surtout perçu pour la musique des mariages. Il existe une protestation contre cet impôt émise par les jurados de la mairie de Grenade, en date du 27 janvier 1517. A cette époque, il est perçu par un certain Fernando Morales alias Ayaya Fisteli qui suivait la coutume de l'époque nazri ${ }^{55}$.

Francisco Núñez Muley se plaint dans son mémorial de la répression car les Rois Catholiques ont permis les musiques morisques (zambras) qui accompagnent le saint sacrement dans les processions et elles accueillent même l'archevêque et accompagnent la messe en l'an 1502. En 1541, la reine

54. Agurlar, Josephine, L'expulsion des morisques de Valence oue par les contemporains, Montpellier, Université, 1976, p. 18.

55. Voir l'appendice de l'oeuvre de Gallego Burín, A. et Gamir Sandóval, A., Los moriscos del reino de Granada según el sinodo de Guadix de 1554, Granada, Universidad, 1968. 
Isabelle du Portugal, défend cette musique contre l'évêque de Grenade, Gaspar de Avalos. Elle ordonne qu'on ne s'adonne pas à des rites religieux lors des auditions de musique morisque ${ }^{56}$. D'ailleurs dans les inventaires de biens meubles des morisques, nous retrouvons divers instruments de musique tels que des tambours morisques, un luth morisque ${ }^{57}$. Lors du premier voyage de Charles Quint en Espagne en 1517, les jeunes filles dansent à San Vicente vêtues à la morisque. Ces danses peuvent figurer une bataille rituelle entre l'été et l'hiver ou entre les vices et les vertus. Elles illustrent aussi les luttes des chevaliers chrétiens contre les maures ${ }^{58}$. Dans les régions où habitent les vieux chrétiens en Espagne, elles sont pratiquées.

Daniel Heartz nous dit que la moresca revêt des formes très diverses. C'est parfois une danse en solo exigeant beaucoup de vigueur ou une danse sur scène en costume somptueux ou encore une danse exécutée par plusieurs hommes ${ }^{59}$. Après l'expulsion des morisques, leurs expressions corporelles sont traitées sur le thème burlesque en intermède au théâtre. L'accent est mis sur les connotations sexuelles et diaboliques assorties d'une imitation satirique de la récitation de la profession de foi musulmane ${ }^{60}$. Ces caractéristiques de la fête morisque, du mariage en particulier, sont connues dans toute l'Europe. On cultive la danse morisque ou morris dance dans le théâtre municipal anglais ${ }^{61}$. Pour l'école des ritualistes ce serait une forme dégradée du culte de la fertilité. Elle se pratique encore aux Etats Unis à l'aube du ler mai. Pour le repas de noce, les animaux sont sacrifiés selon le rituel musulman. Les femmes n'ont pas le droit d'égorger les animaux. Elles les portent aux hommes qui, avant de les tuer, aiguisent leur couteau et testent le fil de la lame dans leur main. Au moment où ils vont égorger, ils tournent la tête de l'animal vers l'Orient et disent Birmillehi, ce qui signifie au nom de Dieu ${ }^{62}$. On immole des animaux suivant le rite Ad Alquibla, en se tournant à midi vers la Mecque. Les morceaux de viande sont distribués

56. Archives de la cathédrale de Grenade. Reales Cédulas, libro II, folio $38 \mathrm{v}^{\circ}-39 \mathrm{r}^{\circ}$.

57. MARTÍNEZ RuIZ, Juan, Inventario de bienes moriscos..., Archives de l'Alhambra, année 1599, Lobras y Nechite (biens confisqués), L 34-51, folio $9 \mathrm{r}^{\circ}$, ligne 32.

58. Marden, C.A., Newton Hall, Cambridge, «Entrées et fêtes espagnoles au XVème siècle», in Fêtes de la Renaissance, Tours, CRR, Actes du XVème colloque de Tours, Paris, CNRS, 1975, 3 tomes, p. 392.

59. Heartz, Daniel, «Un divertisement à Binche», in La fête de la Renaissance...

60. RoIG, Adrien, «Quand les morisques dansaient», in Etudes de moriscologie pendant les 10 dernières années, Colloque de septembre 1993, Zaghouan, CEROMDI (sous presse).

61. LASCOMBES, André, "Théâtre religieux des cycles municipaux, XVème et XVIème siècles», in Chrétiens et musulmans à la Renaissance, 37ème colloque international d'études humanistes, 4-9 juillet 1994, Poitiers, Centre d'Etudes Supérieures de la Renaissance, Paris, Edition Champion (sous presse).

62. КАBO, Raymond, Les esclaves africains face à l'Inquisition espagnole; les procès de sorcellerie et de magie, Montpellier, Université, 1984, p. 14. 
aux pauvres une fois bénis par l'uléma. On prépare du couscous avec la viande de l'animal sacrifié $^{63}$.

C'est la cérémonie du jour du mariage qui détermine l'intégration complète du morisque dans la société des vieux chrétiens. Si cet acte passe inaperçu, il arrivera à rester en Espagne comme c'est le cas pour certains d'entre eux dont les procès d'Inquisition révèleront après la date de l'expulsion les origines morisques qui n'apparaîtront qu'après de longues investigations.

\section{APRÈS LE MARIAGE}

Le lendemain matin après le mariage, les jeunes mariés mangent un ragoût blanc à base de riz appelé la cazuela blanca. Ce met symbolique représente l'abondance et la fertilité que la famille et les amis leur souhaitent. D'ailleurs le riz reste présent avec la même signification de nos jours lorsqu'on le lance sur les mariés à la sortie de l'Eglise.

Les jeunes époux s'enferment pendant les huit premiers jours de leur vie commune. La famille et les amis se chargent de leur approvisionnement. Enfin le neuvième jour, le marié sort. Il va chercher de l'eau à la fontaine et acheter du poisson. Cette coutume est interdite par l'Inquisition. Cette dernière s'oppose aussi à la polygamie qu'elle combat durement auprès des chrétiens. Il semblerait d'après les archives juridiques qu'elle ait mis l'accent sur la lutte contre les musulmans accusés de pratiquer la religion musulmane. Cependant, l'Islam tolère la polygamie ${ }^{64}$. Elle n'est pas inconnue des chrétiens puisque en 1530, l'archevêque de Grenade, Gaspard de Avalos, s'y réfère dans ses instructions. Il affirme que les morisques se marient deux ou trois fois alors que toutes leurs femmes sont vivantes et que pour maintenir cette coutume ils cherchent de faux témoignages. Ou alors ils pratiquent le divorce ou la répudiation définitive ${ }^{65}$ comme aux temps des maures ${ }^{66}$. Le voyageur Jerónimo Munzer affirme lui aussi que les musulmans d'Espagne peuvent se marier avec quatre femmes, qu'ils peuvent répudier facilement. Le contrat de mariage stipule les conditions qui sont variables. La dot est proportionnelle à la situation sociale de la femme (vêtements, colliers, meubles). Les femmes ne peuvent répudier leur époux, mais lorsqu'elles le souhaitent elles leur font la vie impossible. La manière dont chaque système

63. Pour tuer une poule, Jean de Botolla se dirige vers $l^{\prime}$ Alquiba et prononce les mots rituels avant d'égorger l'animal (GARCíA FuENTES, op. cit., p. 216.).

64. KABO, Raymond, Les morisques de Valence, Témoignage d'un contemporain de l'expulsion, Antonio de Corral y Rojas, Montpellier, Université, 1980.

65. Voir lexique final.

66. A.G.S., Cámara de Castilla, liasse 2183. 
juridique conçoit, organise et aménage le divorce, est révélatrice de la conception qu'il se fait du mariage, car légiférer sur le divorce c'est, par contraste, légiférer sur le mariage.

Dans les procès d'Inquisition concernant les morisques s'adonnant à la magie, nous trouvons beaucoup de femmes seules, elles ont recours à cet expédient ou au travail les jours de fêtes pour pouvoir subsister, ce qui est pour les vieux chrétiens une infraction aux règles religieuses. Lucía de Toledo et Ana Hernández de Bustamante ${ }^{67}$ sont deux exemples parmi tant d'autres.. Cette dernière avait été excommuniée pour les nombreuses dettes qu'elle avait. Nous ignorons si son mari était parti dans une autre région ou $s^{\prime}$ il était mort ${ }^{68}$.

María Hernández de Matatoros ${ }^{69}$ avait appris de Mencía Alonso comment savoir si un couple s'aimait bien ou si le mari qui avait abandonné sa femme allait revenir. Avec des grains de blé et d'orge correspondant aux personnes, mélangés à du sel, du charbon et une arête, dans la main, il fallait dire:

\footnotetext{
"Señora Sancta Marta viva fuistes e sancta ansí como atastes la tarasca e la atastes con nuestra Sancta cinta atada, ansí juntéis si éstos se quieren bien los granos de trigo con cebada".
}

En prononçant ces mots on jette le mélange en l'air et on le laisse retomber dans sa jupe pour obtenir une réponse. La morisque dit qu'elle rapproche les couples désunis. Ainsi elle console la femme de Hernán López et lui promet un talisman qui lui permettrait de retrouver l'amour de son époux et l'obligerait à se détourner de ses aventures. Par ailleurs, la situation de la veuve est difficile dans les premiers temps surtout. Elle ne doit pas sortir de chez elle pendant quatre mois et dix jours si ce n'est pour ses besoins essentiels et si elle ne peut en charger quelqu'un ${ }^{70}$. Des arrangements familiaux sont toujours possible dans ces cas précis: un homme peut se marier avec la veuve de son frère après le décès de ce dernier ${ }^{71}$. De même, une femme peut épouser le mari de sa soeur après le décès de cette dernière. Dans ce cas là, il n'est pas question d'inceste, car les notions sont différentes dans les deux communautés religieuses et culturelles en présence. Ce vieux tabou de l'humanité s'oppose à l'union sexuelle de deux personnes déjà unies par un lien de parenté ou d'alliance. Il traduit l'obligation de l'exogamie dont les fondements sont complexes et variables selon les sociétés.

67. AHN, INQ, Tol, liasse 193, n²7, 1545.

68. KABO, Raymond, Les esclaves africains face à l'Inquisition espagnole; les procès de sorcellerie et de magie, Montpellier, Université, 1984.

69. AHN, INQ, Tol, liasse $35, \mathrm{n}^{\circ} 4,1544$.

70. KONTZI, Reinhold, op. cit., p. 444.

71. Ibidem, p. 455. 


\section{FONCTIONS ET SENS DU MARIAGE}

Le mariage n'est pas un sacrement pour le morisque. Cependant il est accompagné de rites religieux, de prières et de chants musulmans. Peu à peu, il est soumis à la cérémonie chrétienne à l'église, qui devient obligatoire pour tous les catholiques. Mais beaucoup d'entre eux se lavent et se changent dès qu'ils arrivent chez eux pour se livrer à leurs anciennes coutumes. L'évolution ou le refus des obligations imposées par le pouvoir dominant sont vérifiables à travers les archives inquisitoriales. La fonction magique qui se cantonne dans l'intimité des familles est plus difficile à percevoir. Nous n'en relevons que quelques traces ça et là qui nous permettent de reconstituer une mentalité qui n'est guère différente de celle des musulmans du Royaume de Grenade ou de ceux des groupes ruraux d'Afrique du Nord à l'heure actuelle. Certains aspects des rites magiques et populaires qui entourent le mariage sont développés dans les livrets aljamiados. Au-delà de ces dimensions religieuses et magiques, il faut mettre l'accent sur le rôle économique, politique et social qui n'est certes pas le moins important, surtout en période de crise.

Bernard Vincent nous dit après un examen des archives de Simancas, que le dénombrement de la ville de Grenade de 1561 révèle que:

"A l'intérieur d'une maison, ne vit qu'un couple et ses enfants, les ascendants ou les collatéraux se trouvent dans les maisons voisines qui donnent soit sur la même rue, soit sur une rue parallèle" ${ }^{\prime 72}$.

Cette vie en commun favorise les alliances par le mariage. Nous en avons un exemple célèbre avec Aben Humeya, le leader du soulèvement grenadin. A ce moment précis nous constatons un retour aux anciennes coutumes. Il choisit trois épouses pour sceller des alliances. Il fait tuer son beaupère et ses deux beaux-frères qui n'ont pas voulu le suivre. Le mariage chez les morisques est donc comme chez les chrétiens, l'axe essentiel pour l'alliance des familles, des clans. Une rupture se conclut aussi par la répudiation de l'épouse. Le musulman recherche le mariage endogame. Il est pratiqué par les morisques. C'est un acte social important car il ponctue l'entrée dans la vie d'adulte et le début de l'apprentissage du rôle de chef de famille, primordial dans le système patriarcal de cette société. Le mariage est donc une grande affaire sauf pour les esclaves. Comme au temps des Wisigoths et après l'invasion arabe, l'essentiel se situe dans les préliminaires. Le père choisit le conjoint après une quête longue et compliquée assurée par la famille. Il est remarquable que les jeunes couples qui sont résolus à se passer de l'autorisation familiale ont un moyen, celui de simuler l'enlèvement. Le rapt fait partie du rituel matrimonial primitif ${ }^{73}$.

72. BERNARD, Vincent, op. cit.

73. BENASSAR, Bartolomé, Histoire des Espagnols, Tome I, VIème-XVIIème siècles, Paris, Armand Colin, 1985, $335 \mathrm{p}$. 
Pour le chrétien, le mariage du morisque est un facteur de possible assujettissement. Dans la Comedia El remedio en la desdicha de Lope, Narváez amoureux est identifié à Mars vaincu par l'amour. Il est poursuivi par Nuño au cours du premier acte dans des vers adressés à l'amour, que nous traduit Adrien Roig:

"Ce vaillant défenseur de la frontière, / cet Andalou redouté, / ce Narváez qui, contre maures, a été un foudre de guerre / aujourd'hui vous le dominez et assujettissez / grâce à une Mauresque" $(\mathrm{I}, 464-469)^{74}$.

Pour le chrétien comme pour le morisque, le mariage peut être aussi un facteur de rebellion ${ }^{75}$. Ils peuvent aussi se conclure pour forger des alliances entre pays mais aussi entre particuliers ${ }^{76}$.

Les esclaves d'origine musulmane ou les morisques sont plutôt accusés pour leurs manifestations traditionnelles correspondant à leurs origines culturelles et religieuses à l'occasion des mariages ${ }^{77}$. C'est le moment pour le morisque ou l'esclave maure, $d$ 'affirmer son attachement à sa religion ou son désir de retourner en terre musulmane. Ainsi Catalina, esclave de doña María de Guzmán de Malaga, est accusée d'être allée à Antequera à un mariage musulman où elle avait rendu grâce à Mahomet et mangé à l'usage des maures. Avec ses compagnons, elle aurait dit à la fin du repas: Que Dieu qui nous rassemble, ici nous rassemble aussi dans notre pays.

Le tribunal de l'Inquisition de Majorque, comme celui de Grenade, rapporte davantage la bigamie des vieux chrétiens ou les idées hétérodoxes en matière de sexualité de ces derniers que les problèmes relatifs au mariage des morisques. Un renégat revenu d'Alger voit sa concubine revenir sous l'aspect d'une magicienne alors qu'il est en plein délire à cause de la fièvre.

74. RolG, Adrien, op. cit.

75. Ainsi le neveu de Garcilaso, malgré l'opposition de l'empereur et de l'impératrice se marie en août 1531 avec Doña Isabel de la Cueva, nièce du duc d'Albuquerque et héritière des biens de cette illustre famille. Il fut exilé de la cour de Tolède et de sa juridiction et arrêté en 1532. Roig, Adrien, «L'Eglogue "Nemoroso" de Sá de Miranda, Llanto pour la mort de Garsilaso", in Hommage à Nelly Clemesy, textes réunis par Gérard Lavergne, Tome II, Nice, Université, 1993, p. 547.

76. “Don Manuel primero casó sucesivamente con Doña Isabel y Doña María de Aragón, hijas de los reyes Católicos, y después con Doña Leonor de Austria, hija de Felipe el Hermoso y de Juana la Loca; Don Juan III con Doña Catalina de Austria, hija de los mismos" in RoIG, Adrien, «Los españoles en el teatro de Gil Vicente», in Encuentros y desencuentros de culturas desde la Edad Media al siglo XVIII, Juan Villegas, Actas Irivine 92, Asociación internacional de Hispanistas, p. 137. "A mulher de D. Joãn III foi sempre mais castelhana que portuguesa e, como o dominava interamente, favorecia o mais possível, os seus patrícios en detrimento mesmo dos de su marido" (BRAMCAMP, Freire Anselmo, Gil Vicente trovalor mestre de balança, Lisboa, Revista Occidente Editora, 1944, p. 244).

77. Cas. 25, Pulianas: "Domingo Hernández Ayex, morisco, vezino de Pulianas, porque se fue con los moros rebelados con otras personas de su casta y se puso nombre de moro, hizo guado y çala y ayuno el ramadan y casó dos hijas a ley de moros con otros moros: habito y carcel perpetua, seis años de galeras", in GARCiA FUENTES, op. cit., p. 105. 
Elle lui aurait retiré sa virilité pour se venger du fait qu'il avait manqué à sa promesse de se marier avec elle.

Les difficultés relationnelles entre homme et femme apparaissent souvent dans les archives juridiques. Le sexe féminin cherche souvent à acquérir une puissance convoitée à l'intérieur du couple. Ainsi Cecilia Pérez recommande des poudres fabriquées à base de cervelle d'âne à administrer au mari de femmes battues. Après ce traitement, il ne maltraitera plus son épouse, à tel point qu'elle pourra même recevoir d'autres hommes chez elles. Cette image se retrouve dans la littérature sur le thème bien connu de la mégère apprivoisée. La femme irrascible et autoritaire, maure, est illustrée par l'exemple 35 du Conde Lucanor ${ }^{78}$. Elle est apprivoisée par son mari. Ce personnage n'est pas sans rappeler la Katharina de Shakespeare ${ }^{79}$. Par ailleurs une esclave morisque d'origine marocaine porte le cas à son paroxisme puisqu'elle fait fuir son dernier mari (elle a réalisé trois mariages) à cause de son caractère irrascible $e^{80}$. Ce type de la femme indomptable surgit dans une société patriarchale où l’homme domine.

Comme pour les chants et danses morisques traditionnelles, nous pouvons distinguer entre 1492 et 1570 trois grandes étapes dans l'évolution. D'abord les manifestations traditionnelles et festives sont permises entre 1492 et 1529. Ensuite la situation empire (1530-1565) jusqu'à l'interdiction complète (1566-1570), juste avant la rebellion des morisques. On leur interdit

78. Don Juan Manuel, El conde Lucanor y otros cuentos, Barcelona, Bruguera, 1978, 891 p.

79. SHAKESPEARE, W., La mégère apprivoisée [1594]: Le personnage de Kathatina est le type même de la femme irrascible dominée brutalement par son mari. C'est un modèle des plus anciens. Dans la littérature, cette figure est aussi fréquente que la femme portant culottes qui mène son mari par le bout du nez. Ce genre a été traité magistralement par Chancer dans «La femme de Bath» des contes de Canterbury (vers 1384). Cette jeune femme, de caractère insupportable par son entêtement, veut toujours avoir le dernier mot; elle aspire cependant à trouver un mari. Elle le montre dans les paroles furieuses qu'elle adresse à son père en parlant de sa soeur Bianca "Je danserai pieds-nus le jour de ses noces, et j'irai garder les singes en enfer". Le mariage apprivoise la mégère.

Chancer Conte de Canterbury (1350), «La bourgeoise de Bath» (The wife of Bath's Tale). Ce conte est précédé d'un prologue, magistrale satire des femmes et du mariage mis dans la bouche de la bourgeoise type parfait de la maîtresse femme. Elle soutient que son rôle est de dominer son mari.

DESCHAMPS, Eustache, Le miroir du mariage. GOWER, John, «Confessio amantis», Histoire de Florent: Un chevalier est contraint de donner dans un délai de douze mois, pour échapper à la peine capitale, la réponse exacte à la question: "Quel est le plus grand désir des femmes?". Une vieille sorcière lui apprend, à condition qu'il l'épouse, que la réponse est: "domination". Il s'exécute avec répugnance mais goute ensuite le bonheur inespéré de voir la sorcière se muer en une gracieuse jeune fille. Origine irlandaise de ce conte. LAFFONTBompiani, Dictionnaire des auteurs, Paris, Société d'édition des dictionnaires et encyclopédies, 1964, 2 tomes. Id., Dictionnaire des oeuores, Paris, Société d'édition des dictionnaires et encyclopédies, 1962, 4 tomes. Id., Dictionnaire des personnages, Paris, Société d'éđition des dictionnaires et encyclopédies, 1962, 2 tomes.

80. Voir texte en annexe. 
de jouer, chanter ou danser même pendant les mariages car certains de leurs chants mentionnent Mohamed ${ }^{81}$.

La plupart des coutumes sont d'origine musulmane, encore renforcées par l'arrivée des esclaves barbaresques, des renégats (Baléares) ou des marocains connus sous le nom de morisques qui arrivent au Portugal comme esclaves. D'après les documents inquisitoriaux, certains de ces hommes et femmes voyagent par le jeu des ventes, mais aussi lorsqu'ils obtiennent leur liberté $^{82}$. Morisques et esclaves d'origine musulmane se considèrent comme frères en religion et alliés potentiels. Les contacts sont fréquents. Les traditions afférentes au mariage se transmettent donc dans le temps mais aussi dans l'espace pour renforcer par ce biais le caractère oriental des rites. Cependant l'héritage païen, préislamique ou préhispanique reste vivant et se mêle aux caractéristiques précédentes. Mais la répression et la conversion conduisent les coutumes morisques à une évolution constante, à une réduction provoquée par l'exil et par l'appauvrissement culturel et financier. La destabilisation des rites du mariage est le reflet de l'acculturation de la communauté morisque dirigée par le pouvoir chrétien.

Dans les années qui précèdent l'expulsion, le mariage est un luxe auquel accèdent de plus en plus difficilement les morisques par manque d'argent. Les chrétiens en avaient sans doute conscience puisqu'ils représentent la morisque de la Pícara Justina ${ }^{83}$ célibataire malgré son grand âge. Le mariage est le juste reflet de la société dans laquelle il se réalise. Pendant ce moment de fête les conflits existants explosent. Ainsi pendant cette cérémonie et cet acte social, les manifestations d'identité musulmane vont s'exacerber et s'exprimer pour bien montrer les aspirations du morisque. Mais à la fois l'influence religieuse de la majorité chrétienne dominante va tenter de les étouffer surtout après la conversion forcée. Ce processus progressif d'intégration se poursuivra jusqu'à l'expulsion mais la résistance cachée, possible à l'intérieur des familles, montre bien que la grande majorité de ce peuple reste très attachée à ses coutumes musulmanes et à ses rites ancestraux. D'ailleurs, ceux qui arrivent à s'intégrer par le mariage ne font plus parler d'eux. Ils suivent alors les habitudes des vieux chrétiens. Nous en retrouvons certains après 1610 qui sont même entrés en religion et qui donc subissent le célibat obligatoire de cet état, attitude extrême en totale opposition avec la mentalité profonde de leur peuple d'origine.

Les pratiques matrimoniales spécifiques aux musulmans, régressent d'abord mais resurgissent violemment lors de la guerre de Grenade de 1568-

81. Fernández Manzano, Reynaldo, «La música de los moriscos del Reino de Granada», in Le Vème centenaire de la chute de Grenade, Tunis, CEROMDI, 1993, pp. 257-273.

82. Alvaro Bazán, INQ, ADC, liasse 337, $n^{\circ} 4826$, année 1594, esclave turc converti et ayant acheté sa liberté.

83. López De Ubeda, Francisco, La Pícara Justina, Autores posteriores a Cervantes, Madrid, BAE, $n^{\circ} 33,1950$. 
1570. Les mariages mixtes, très peu nombreux, ont permis à certains de rester lors de l'expulsion car leur assimilation faisait qu'ils ne se distinguaient plus de la majorité chrétienne. Les échanges inévitables entre les coutumes des deux communautés, ont atténué les caractères spécifiques du mariage morisque. En Espagne, les coutumes locales peuvent être un legs musulman. Ainsi dans les villages de Castille et dans ceux de Alpujarras, les nouveaux mariés continuent à prendre leurs repas séparément dans leur famille d'origine durant la première année.

L'union durable de l'homme et de la femme est une constante de l'espèce humaine qui obéit à une loi de nécessité physique, sociale, morale et affective. La permanence et l'universalité du droit du mariage expriment la nécessité d'institutionaliser et de façonner le couple humain. La manière dont le mariage est saisi par le droit, quant à la formation et à la dissolution du lien conjugal et quant à la nature des relations entre époux, trace les ligne de partage des grandes civilisations et définit aussi les seuils de leur évolution historique et sociologique. Le droit du mariage, pièce maîtresse du droit de la famille est le produit de nombreux facteurs idéologiques, religieux ou moraux mais aussi politiques, sociologiques, démographiques et économiques, dont les rôles respectifs varient d'un pays à l'autre, ou d'une époque à une autre.

Dans l'Espagne du XVIème siècle, l'institution sociale du mariage morisque et sa réalité anthropologique qui évoluent du rite musulman au rite chrétien, constituent une des données fondamentales de cette civilisation. Dans le contexte d'acculturation, la fête va vers son déclin à cause de l'appauvrissement culturel et financier de la minorité morisque mais aussi de par la situation économique espagnole qui empire.

\section{LEXIQUE DU MARIAGE DES MORISQUES ${ }^{84}$}

Abiçania: ablution rituelle des organes sexuels.

Abiqueçiti: Cette maladie, la lèpre, permet à la femme de quitter son mari, elle peut le faire aussi s'il est agité par les esprits, s'il est impuissant ou s'il lui manque une partie de ses organes sexuels. Cependant on lui accorde un délai d'un an pour la guérison.

Aborramiento: ou aborrençia (aborreçer, aborrir), détester.

Abortamiento: action d'avorter.

Absortar: répudier, donner la liberté.

84. Pour les références des textes où les mots de littérature aljamiada sont employés voir: Galmés de Fuentes, Alvaro; SÁnChez Alvarez, M.; Rodríguez, Vespertino y Villaverde AMIEvA, J.-C., Glosario de voces aljamiado-moriscas, Oviedo, Universidad, Biblioteca AraboRománica, 1994, 762 p. 
Acabad: descendance, postérité.

Aççihre: la magie.

Aççihror: magicien.

Aç̧eciones: les avoirs, les possessions.

Açidente: défaut, faute.

Açihrado: ensorcelé enchanté. Cet adjectif est formé sur le mot arabe çhir, enchantement, ensorcellement.

Açihrero / Alçihrero: magicien enchanteur.

Agurarrás: eau de rose.

Albarán: certain type de talisman.

Alcandora: vêtement.

Alcatil: notaire.

Alcohalarse: mettre du khôl aux yeux.

Alcuzcuz: couscous.

Alfisás: bague ornée de pierres précieuses.

Aliginis: djinn.

Alhanna = Alheña: henné / alheñar / alheña / alheñada: henné.

Alherfe $=$ alharfe, alherce $=$ alherzi, alherzi: amulette talisman .

Alhidal: maquillage des paupières.

Alhiñan: mal d'amour, nostalgie.

Alkuélula(s): cris féminins de peine ou de joie.

Alkuli: bijoux de femme.

Alictinja: ablution des organes sexuels.

Al'iddat: période d'attente pour la veuve avant son remariage.

Al'ifrit, es: génie malveillant.

Alkinya: surnom.

Alkohol: khôl pour les yeux, alkoalarse = alcoalarse, alkoholera, alkuhulado: maquillé avec du khôl - alqohalarse = alcohalarse.

Almadyu: liqueur seminale.

Almahra: dot que le fiancé offre à la fiancée.

Almajud: pièce en bois en forme d'aiguille qui sert à mettre le khôl sur les paupières.

Almani = sémen.

Almania: éjaculation.

Almiçke = almizcle: parfum, musc .

Almchálem: adulte, celui qui a atteint la puberté. 
Almubarat: libération réciproque entre le mari et la femme.

Alqagutear = alcahuetar, Alquawete: entretemetteuse.

Alwali: ami ou parent qui représente la fiancée lors du mariage et qui la conduit à son mari.

Alwarsi: pierre précieuse.

Algaquta: rubis, pierre précieuse.

Alluntamiento: union.

Ama: concubine.

Amamiento: amour.

Amanta: personne aimée.

Ammor: amour.

Amorío: amour.

Annusra: invocation qui consiste à écrire un verset du Coran à l'encre sur un parchemin, puis on le dissout dans l'eau et on le fait boire au patient.

Ansara: fête de la Saint Jean Baptiste, origine païenne (solstice d'été), naissance du prophète Yahyá.

Aqasarse: casarse.

Aras: mariage.

Arguillos: boucles d'oreilles.

Arrakadas: boucles d'oreilles.

Arreamiyento: bijoux, préparatifs, ornements.

Arrear: préparer, orner.

Arreas: ornements.

Asigar: compensation, pacte par lequel quelqu'un marie la fille ou la parente de quelqu'un d'autre en lui concédant à la fois la main de sa propre fille ou parente, sans que ni d'un côté ni le l'autre on n'attribue une dot (interdit par Mahommet).

Atankada: répudiée définitivement. La répudiation définitive ou triple répudiation consiste à dire trois fois à la suite la formule de répudiation: c'est interdit par le Coran (en une seule fois). Le mari ne peut plus reprendre sa femme ainsi répudiée sauf si elle est restée veuve après un nouveau mariage consommé.

Atankante: celui qui répudie définitivement.

A usanza de moros: expression utilisée par les Inquisiteurs pour parler du mariage morisque traditionnel.

Azzina: adultère.

Bigenkerigen: aimé.

Birsinal: virginal. 
Bulermin: aigue-marine, béryl.

Cagi / caydi le cadi: le juge.

Casado y velado: expression utilisée par les Inquisiteurs pour le mariage de rite chrétien.

Çinta: ceinture.

Coftán: caftan, tunique.

Chin: djinn.

Choyal: bijou.

Chuntar: rassembler.

Demón: démons.

Dulterio: adultère.

Ellehan: accusations jurée d'adultère.

Enestrólogo: astrologue.

Enpreñar: tomber enceinte.

Entokar: mettre la toque ou le turban.

Entrar con: avoir des relations charnelles, consommer le mariage.

Enviudecer: rester veuf.

Estrela: étoile.

Estrerelagía: astrologie.

Desposado: marié.

Fado : destin.

Flor: purgaçión: les règles, la menstruation.

Fosús: bagues garnies de pierres précieuses.

Fragança: parfum.

Fresca de vista: belle (arabisme).

Golor: odeur.

Guçl: ablutions rituelles avant la prière.

Gudisiador: astrologue.

Haguatimes: sceaux mystérieux.

Halal: licite.

Hami: Beau-père.

Harám: illicite/ haramante: celui qui fait haram.

Hirce: talisman.

Holca: anneau, boucles d'oreilles.

Holgar: avoir des relations sexuelles.

Jazmi chico: système cabalistique de valeur des lettres de l'alphabet à des fins divinatoires. 
Jeneloya: généalogie, lignage.

Kita: divorcé.

Kitassión: divorce.

Kitamento: abandon.

Konjugalidad: mariage.

Korrompida: pas vierge.

Magita: femme qui joue du tambourin pour le mariage.

Maridanza: accord des gens mariés.

Maridar: casar.

Safrán: zafarán: safran.

Tahararse: faire des ablutions rituelles, se purifier, se laver.

Tahur: ablutions rituelles.

Tokado: couvert d'une toque.

Toqador: toque.

T'rangado (attalaq): répudiation définitive, terme juridique du XIIIème siècle (Zurita, Teruel, Albarracín), attribuer légalement quelque chose à un nouveau possesseur ou vente aux enchères d'un bien au profit d'un créancier, toujours en vigueur en Aragon en 1531 (Fueros aragoneses).

Xaneloya: généalogie.

\section{APPENDICE DOCUMENTAIRE}

Interdiction des coutumes morisques.

- Capítulo acordado en la junta de la villa de Madrid sobre las reformas de las costumbres de los moriscos de Granada 1566:

"Cuanto a las bodas, se ordenó que en los desposorios, velaciones y fiestas que se hiciesen, no usasen de los ritos, ceremonias, fiestas y regocijos de que usaban en tiempo de moros, sino que todo se hiciese conformándose con el uso y costumbre de la Santa Madre Iglesia y de la manera que los fieles cristianos lo hacían: y que en los días de bodas y velaciones tuviesen las puertas de la casa abierta, y lo mismo hiciesen los viernes en la tarde y todos los días de fiesta; y que no hiciesen zambras ni leilas con instrumentos ni cantares moriscos en ninguna manera, aunque en ellos no cantasen y ni dixesen cosa contra la religión cristiana ni sospechosa de ella..." ${ }^{85}$.

85. Transcription de l'archive de l'Alhambra par Fernando Mancano Reinaldo. 
Mariage mixte des morisques.

Cédule promulguée lors du séjour de Charles Quint à Grenade en $1526^{86}$ :

"Hazemos merced a los cristianos viejos que casaren en este reyno con cristianas nuevas e a las cristianas viejas que casaren con cristianos nuevos e a los cristianos viejos que fueren a vivir entre cristianos nuevos que sean libres y exemptos de huéspedes así de los de nuestra corte como de gente de guerra e otros qualesquier y que no den ropa ni bestias de guía ni aves ni otra cosa alguna por vía de aposento e demás desto por les hazer más merced a las tales personas que hizieren lo suso dicho les prometemos que luego que nos conste dello les haremos merced para ellos y para sus herederos y sucesores de les dar y señalar de lo realengo e público y concegil algunas roças e tierras e términos".

\section{La mégère.}

- Inq., Lis, procès $n^{\circ} 4184$, folio $7 r^{\circ}-8 r^{\circ} 87$.

“...Perguntado (Cosme Gonçalvez) se era casado, disse que sy que era casado com Luzia de Bryto, mourisca preta forra, e que nam fazia vida com ella porque era molher de forte condição e que fora casada tres vezes e com elle quatro, e que todos os tres marydos se finaram com mão vida e payxão della. E o derradeyro se chamava Joam Delgado, estando doente em Evora, ella o deyxou em cama e levou o que elle tynha e se foy pera Beja. E despois tornou e o levou a Estremoz dizendo que o hia curar; e daly a dous ou tres dias tornou dizendo que seu marydo era falecido. e com o prymeyro se foy a Castella omde elle moreo, e ella se tornou pera Portugal. E outro lhe morreo na cadea. E elle, Cosme Gonçalvez, despois de cristão, dahy a tres meses se casou com ella a porta da Igreja de Nossa Senhora de Marvylla da villa de Samtarem. E logo dahy e certou dias lhe fogio camynho de Castella a Velha, e the levou vimte e cinco mil reis. E dahi a hum mes se tornou ella a casa de Gaspar Gonçallvez e lho rogou, e elle por amor delle tornou a recolhella. E estiveram em casa como casados tres ou quatro meses, e dahy lhe fogio pera Tamgere omde esteve tres ou quatro annos. E dahy se tornou e veyo a casa de dona Branca de Vilhana, e por tho ella rogar, fizeram vida seis ou sete meses, e dahy veyo a dizer que elle que a querya afogar de noyte com huma corda e se foy ao corregedor fazer queyxume delle. E por o corregedor nam achar synal do que ella dizia nem prova, the disse que se fose embora e que fizese vida com sua molher. $\mathrm{E}$ dahi se foy pera Sevylha e ella se foy pera Alemtejo, de maneyra que nam fez mays vida com ella, nem tinha della filho nem filha. E que ella vive a Sam Vicente de fora nesta cidade, e que e molher muito forte e pera nynguem poder fazer vida com ella como de tudos se podem enformar.

Preguntado que mulheres tinha agora em casa, disse que tinha huma molher mourisca ja velha que se chama Maria Fernandez, forra, a qual lhe faz de comer e the lava a sua roupa porque he lavandeyra, e que ella vay dormyr a casa de Luiza de Camelo, mourisca que vive ahy, a Sam Roque, e que algumas vezes vay a sua casa huma india por nome Catarina d'Aguyar que he de Ana de Myranda que vive aquy sobre o chafaris do Rosyo, a qual india he sua amyga; e asy vay a sua casa tambem a dita mourisca e homens, e que comyão em sua casa e bebyam algumas vezes...".

86. A.G.S., Cámara de Castilla, liasse 2161, folio 101, 8 décembre 1526.

87. BOUCHARD, Ahmed, op. cit., pp. 585-586. 